\title{
2012 Jacquet-Lucas Award for Excellence in Metallography
}

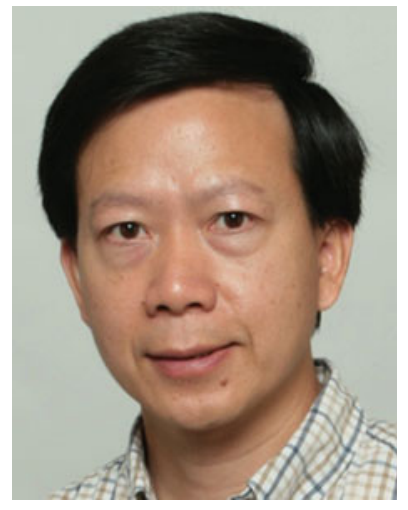

The 2012 recipient of the Jacquet-Lucas Award is Dr. Zhiping Luo from Fayetteville State University, N.C., for his entry entitled Novel Shape Memory Alloy Nanowires.

The ASM Metallographic Award was established in 1946 for the best entry in the annual ASM metallographic competition. In 1958, it became known as the Francis F. Lucas Metallographic Award.

In 1972, ASM joined with The International Metallographic Society (IMS) in sponsoring the Pierre Jacquet Gold Medal and the Francis F. Lucas Award for Excellence in Metallography. This award has been endowed by Buehler since 1976.

Dr. Luo is an associate professor of the Department of Chemistry and Physics, and manager of the Electron Microprobe Facility, Fayetteville State University. He received his Ph.D. from the Chinese Aeronautical Establishment in 1994. He worked at Beijing Institute of Aeronautical Materials, China, did postdoctoral research at the

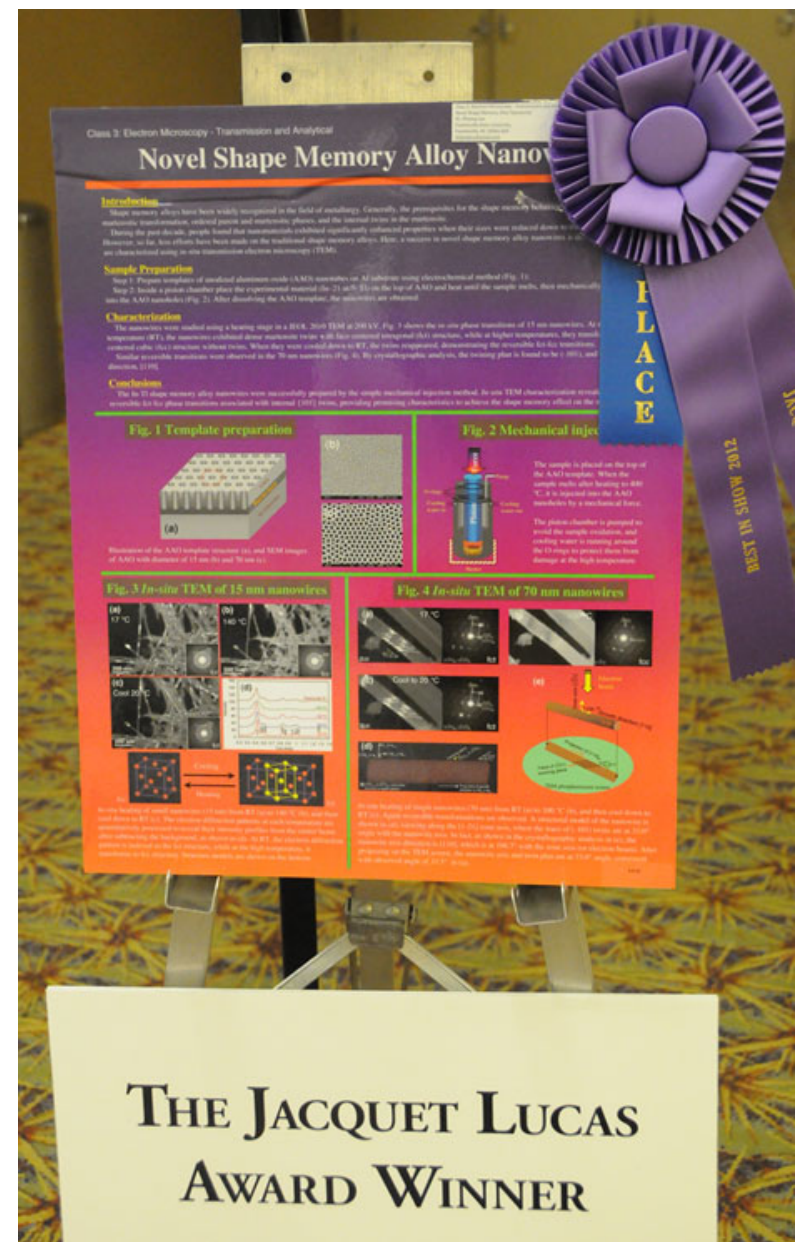

Okayama University of Science, Japan, and was visiting scholar and assistant scientist at Argonne National Laboratory, Ill. From 2001 to 2012 he was research scientist and graduate faculty member at Texas A\&M University. 
$\mathrm{He}$ is widely published and serves as a reviewer or editorial board member for 30 journals. Dr. Luo received the DuBose-Crouse Award from IMS and the Professional Technical Staff Award from the Microscopy Society of America in 2008.
This paper highlights Dr. Luo's findings and expands on his award-winning entry. 